\title{
A Novel High Controllable Voltage Gain Push-Pull Topology for Wireless Power Transfer System
}

\author{
Qichang Duan *, Yanling Li, Xin Dai and Tao Zou \\ School of Automation, Chongqing University, 174 Shazheng Street, Shapingba District, Chongqing 400030, \\ China; liyanling1978@gmail.com (Y.L.); daixin@cqu.edu.cn (X.D.); 20161301007@cqu.edu.cn (T.Z.) \\ * Correspondence: duanqichang1953@gmail.com; Tel.: +86-23-6510-6188
}

Academic Editor: Chunhua Liu

Received: 2 February 2017; Accepted: 29 March 2017; Published: 1 April 2017

\begin{abstract}
Wireless Power Transfer (WPT) is commonly used to transmit power from a transmitting coil to various movable power devices. In the WPT system, due to a resonant tank inherent characteristic, the system cannot achieve a high output voltage gain. This paper proposes a novel current-fed push-pull circuit to realize high output voltage gain by adding a bi-directional switch between the resonant network and inverter. To obtain a high voltage gain, this paper proposes energy storage and energy injection mode to realize an energy boost function. A duty cycle control method for mode switching is also proposed. The proposed method allows the converter to operate with a variable voltage gain over a wide range with high efficiency. Experimental validation shows that the system gain of a proposed circuit can achieve a variable gain from 2 to 7 of which the converter can be two times higher than the classical system with the same condition.
\end{abstract}

Keywords: wireless power transfer; push-pull circuit; voltage gain

\section{Introduction}

The Wireless Power Transfer (WPT) system as a novel technology can realize power wireless transmission from power supply to electrical equipment with the aid of magnetic coupling. With its rapid development, more and more applications have appeared in electrical vehicles, biomedical implants and cell phone areas [1-6].

More and more applications in WPT technology require low DC voltage input and high voltage output. These applications include the Photovoltaic (PV) system, battery power supply system and Universal Serial Bus (USB) powered devices. However, it is not easy for the WPT system to obtain high voltage gain according to the following reasons-first, due to the WPT system being a weakly coupling system with very low coupling coefficient $k$ (normally below 0.2$)[7,8]$ and the coupling coefficient of transformer can almost reach 1 . The second reason is the inherent characteristic of the resonant network. There are four fundamental resonant topologies SS, SP, PS, and PP (S and P denotes series and parallel topology, respectively). Series resonant network exhibits voltage source characteristics that cannot obtain a high voltage gain. The parallel resonant network exhibits current source characteristics that obtain high voltage gain on the light load condition. However, for heavy load conditions, it still cannot obtain high voltage gain. Furthermore, its reflecting impedance will bring relatively large frequency drift, which may cause a large reduction in output power $[9,10]$. For the same reason, composite resonant networks such as Inductor Capacitor Inductor (LCL), Inductor Capacitor Capacitor (LCC), and Capacitor Inductor Capacitor (CLC), which are combinations of the series and resonant topology, cannot reach high voltage gain. Reference [11] analyzes wireless charging circuit characteristics under hybrid compensation topology. The analysis results show that the output voltage gain is below three in hybrid compensation topology. 
To achieve high output voltage gain, the classical method is implemented by placing an additional Boost converter at the primary or secondary side. However, the added Boost converter will increase the volume and weight of the whole system [12,13], and make the system complicated to control. There are few papers related with voltage gain improvement. Aiming at voltage gain optimization and control, Reference [14] proposes a uniform voltage gain control method. This method is implemented by control system operating frequency. However, the method only aims at improving the robustness against misalignment. Reference [15] proposes a detached magnetic core to improve the voltage gain method. The obtained voltage gain is 0.83 . Reference [16] proposes an S/SP topology converter to obtain constant voltage gain. However, the voltage gain cannot be adjusted and will be very sensitive to frequency drift on the high gain condition.

In order to obtain a high and controllable output voltage gain WPT system, this paper proposes a novel current-fed push-pull converter at the primary side. A pair of Insulated Gate Bipolar Transistor (IGBT) switches, which act as a directional switch, is added in front of the resonant network to isolate the inverter and resonant network. An energy storage and injection switching mode is proposed to control the energy flowing into the resonant network. A switching duty cycle regulation method is also proposed to reach high voltage gain.

\section{High Output Gain Push-Pull Circuit}

The proposed high output gain push-pull circuit is shown in Figure 1. Compared with traditional push-pull circuits, the proposed circuit adds two additional switches $S_{3}$ and $S_{4}$ to form a bi-directional switch. At the primary side, a DC power supply is a series with an inductor to form a quasi-current source. A push-pull transformer including $L_{1}$ and $L_{2}$ is utilized to divide the DC current in half, so that the current flowing into the resonant tank is approximately a square waveform with half the magnitude of the input DC current. The primary side uses two main switches $\left(S_{1}\right.$ and $\left.S_{2}\right)$ with a common ground and two auxiliary switches $\left(S_{3}\right.$ and $\left.S_{4}\right)$ in series with a parallel-tuned resonant tank, which consists of a resonant capacitor $C_{P}$, a resonant inductor $L_{P}$ and equivalent series resistance $R_{P}$. The secondary side comprises a parallel resonant tank, which consists of a resonant inductor $L_{S}$, equivalent series resistance $R_{S}$, and a resonant capacitor $C_{S}$. With the rectifier bridge $\left(D_{1}-D_{4}\right)$ and Inductor Capacitor (LC) filter network, AC energy is transformed to DC output to the load $R$.

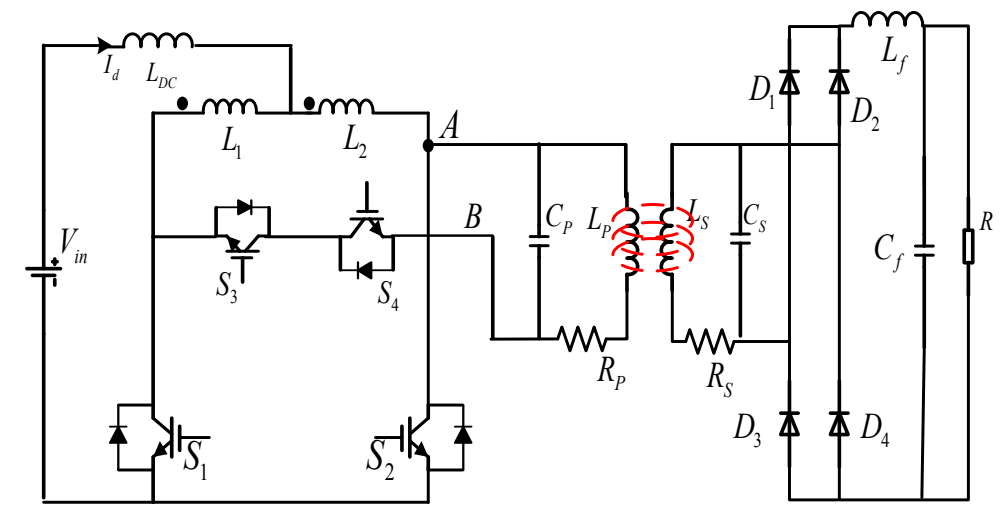

Figure 1. High controllable voltage gain push-pull topology.

Aiming at voltage gain promotion, this paper proposes a resonant energy promotion method at the primary side. An energy storage mode is realized by shorting the DC inductor and phase-shifting transformer. An energy injection mode is realized by combining the storage energy and DC input energy together and outputting to the resonant tank. The switching between the energy storage and injection mode is implemented by auxiliary switch pair $S_{3}$ and $S_{4}$.

Figure 2 shows fundamental operation principles of the proposed method. The pulses and current waveforms of the proposed circuit switches are shown. $V_{G E 1}$ to $V_{G E 4}$ denotes the driving signals of 
switches $S_{1}$ to $S_{4}$, respectively. The current waveform of $i_{L 2}$ is similar to the current waveform of $i_{L 1}$, except for half-cycle delay. The function of anti-series switches $\left(S_{3}\right.$ and $\left.S_{4}\right)$ is to control the connection between resonant tank and push-pull circuit. During one full switching cycle, the circuit operation can be divided into the following four modes and can be shown in Figure 3.

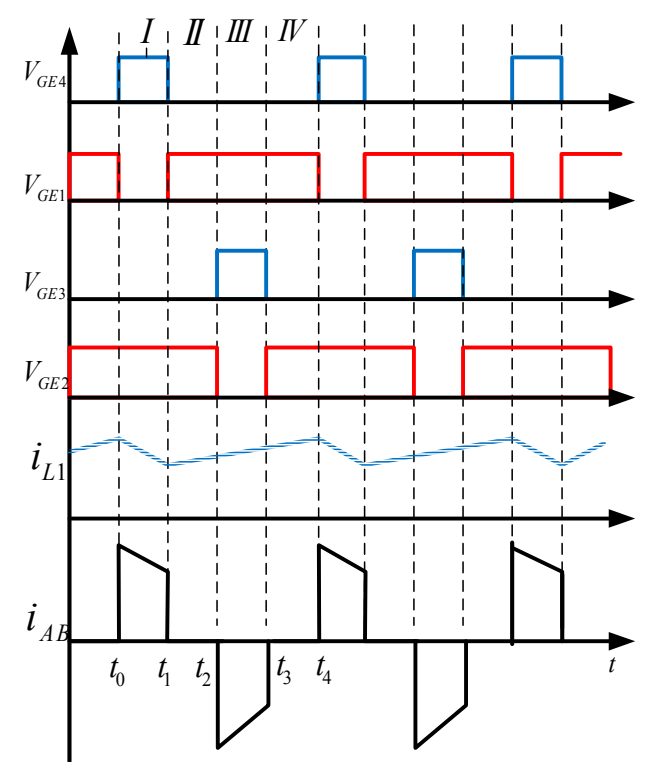

Figure 2. Operation principle of the push-pull topology.

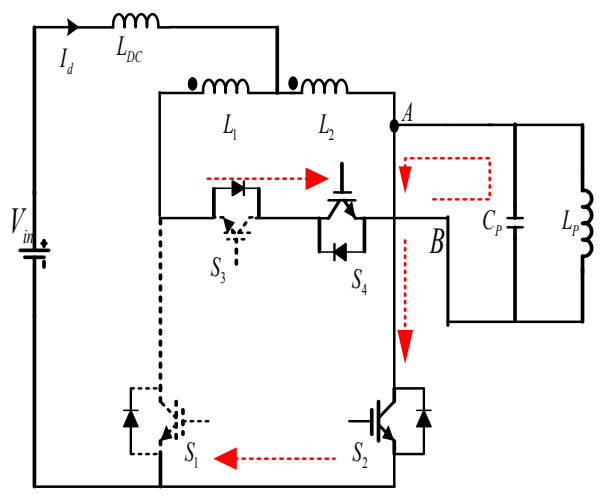

(a)

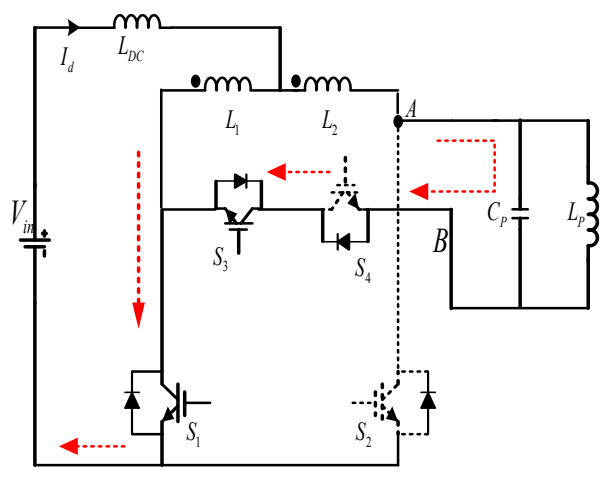

(c)

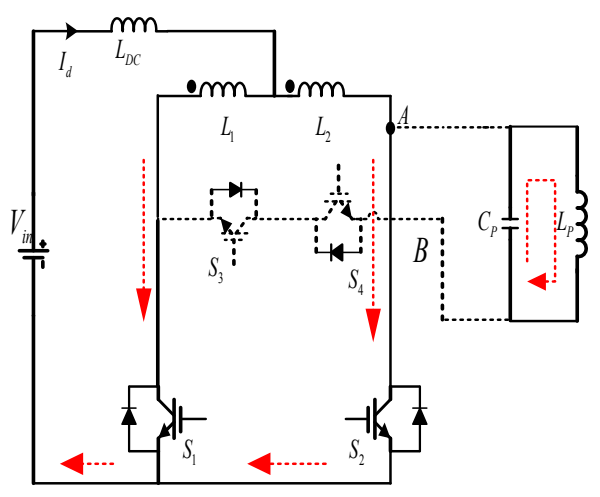

(b)

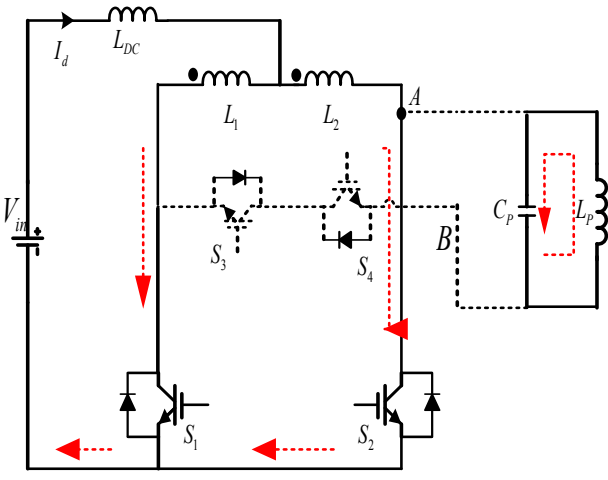

(d)

Figure 3. Operating modes of the proposed circuit in one cycle. (a) Mode I; (b) Mode II; (c) Mode III; and (d) Mode IV. 
Mode I: $t_{0}-t_{1}$ : In this mode, switches $S_{2}$ and $S_{4}$ are turned on; switches $S_{1}$ and $S_{3}$ are turned off. The operation of this mode is shown in Figure 3a. The energy stored in $L_{1}$ is transfer into the resonant circuit by switch $S_{4}$ and the reverse diode of $S_{3}$; switch $S_{2}$ is remaining conduction, so that the current flowing $L_{2}$ is rising slowly and $L_{2}$ is still working in the state of storage.

Mode II: $t_{1}-t_{2}$ : In this mode, switches $S_{1}$ and $S_{2}$ are turned on and switches $S_{3}$ and $S_{4}$ are turned off. The operation of this mode is shown in Figure $3 \mathrm{~b}$. Switches $S_{3}$ and $S_{4}$ are turned off and the resonant circuit enters the state of free energy oscillation between $L_{P}$ and $C_{P}$. Switches $S_{1}$ and $S_{2}$ are turned on and $L_{1}$ and $L_{2}$ are both working in the state of storage.

Mode III: $t_{2}-t_{3}$ : In this mode, switches $S_{1}$ and $S_{3}$ are turned on; switches $S_{2}$ and $S_{4}$ are turned off. The operation of this mode is shown in Figure 3c. The energy stored in $L_{2}$ is transferred into the resonant circuit by switch $S_{3}$ and the reverse diode of $S_{4}$ and the current flowing through $L_{2}$ is decreasing; switch $S_{1}$ is remaining conduction, so that the current flowing $L_{1}$ is rising slowly and $L_{1}$ is still working in the state of storage.

Mode IV: $t_{3}-t_{4}$ : This mode is similarly with Mode II, switches $S_{1}$ and $S_{2}$ are turned on and switches $S_{3}$ and $S_{4}$ are turned off. The operation of this mode is shown in Figure 3d. Switches $S_{3}$ and $S_{4}$ are turned off and the resonant circuit enters the state of free energy oscillation between $L_{P}$ and $C_{P}$. Switches $S_{1}$ and $S_{2}$ are turned on and $L_{1}$ and $L_{2}$ are both working in the state of storage.

\section{Voltage Gain Analysis}

Assuming that the resonant cycle of the circuit is $T$, and the switching duty cycle of $S_{1}$ and $S_{2}$ is $D$; correspondingly, the duty cycle of $S_{3}$ and $S_{4}$ is $(1-D)$. According to the volt-second balance of inductors $L_{1}$ and $L_{2}$, the average voltage across $L_{1}$ and $L_{2}$ is equal to zero during one switching cycle period. During the steady state, the current flows through $L_{1}$ and $L_{2}$ is equal so that the energy stored in inductors $L_{1}$ and $L_{2}$ is equal as well. Next, the paper will calculate the output gain based on the fact that the energy stored and released in inductor $L_{1}$ is equal during one switching cycle.

In the steady state, the supply current is $I_{d}$, and the current flowing through $L_{1}$ or $L_{2}$ is $I_{d} / 2$. Assuming the resonant network terminal voltage is $U_{A B}$, thus the volt-second balance equation can be obtained as

$$
V_{\text {in }} \frac{I_{d}}{2} D T=\left(U_{A B}-V_{i n}\right) \frac{I_{d}}{2}(1-D) T .
$$

Thus:

$$
U_{A B}=\frac{V_{\text {in }}}{1-D} \quad(0.5 \leq D<1)
$$

Note that duty cycle of switches $S_{1}$ and $S_{2}$ is no less than 0.5 . It is because when the duty cycle is less than 0.5 , switches $S_{1}$ and $S_{2}$ will enter the state of turning off at the same time; correspondingly, switches $S_{3}$ and $S_{4}$ will enter the state of turning on. It will result that the current of $L_{1}$ and $L_{2}$ drops sharply to zero and the current will become discontinuities. On the assumption, system equivalent circuit can be shown as Figure 4.

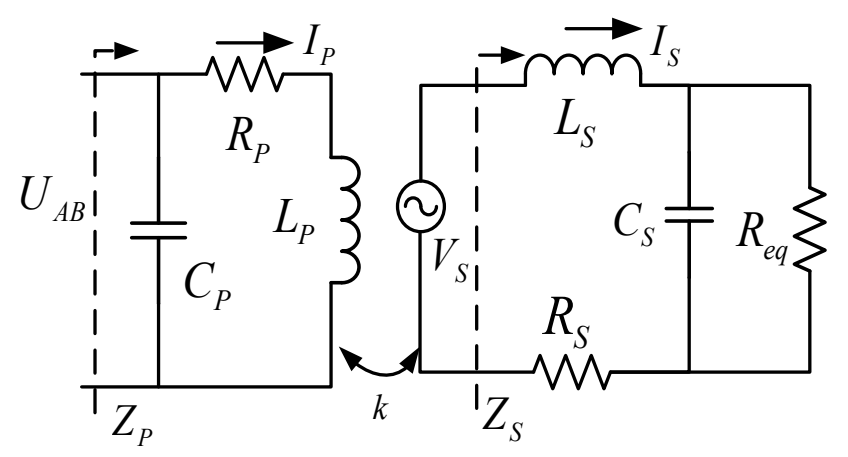

Figure 4. Equivalent circuit of the push-pull circuit. 
At the secondary side, according to the energy balance equation, the equivalent resistance $R_{e q}$ of DC part including rectifier, filter and load at the secondary side is

$$
R_{e q}=\pi^{2} R / 8
$$

The reflection impendence from the secondary to primary side can be expressed by

$$
R_{r e f}=\omega^{2} k^{2} L_{P} L_{S} / Z_{S}
$$

where $Z_{S}=\left(j \omega L_{S}+R_{S}\right)+R_{e q} /\left(j \omega C_{S} R_{e q}+1\right)$ is the input impendence of secondary resonant network. Its resonant angular frequency is $\omega=2 \pi f$.

The input impendence of the push-pull network can be expressed as

$$
Z_{P}=\frac{j \omega L_{P}+R_{P}+R_{r e f}}{j \omega C_{P}\left(j \omega L_{P}+R_{P}+R_{r e f}\right)+1} .
$$

The resonant current of the primary side $I_{P}$ can be expressed as

$$
I_{P}=U_{A B} / \sqrt{\left(\omega L_{P}\right)^{2}+\left(R_{P}+R_{r e f}\right)^{2}} .
$$

It is well known that the inductive voltage source of secondary side can be expressed as

$$
V_{S}=\omega k I_{P} \sqrt{L_{P} L_{S}} .
$$

On the resonant condition $\omega^{2} L_{S} C_{S}=1$, the output voltage $V_{O}$ the load can be obtained as

$$
V_{O}=\frac{R_{e q}}{\left(j \omega C_{S} R_{e q}+1\right)} \frac{j \omega k U_{A B} \sqrt{L_{P} L_{S}}}{\left(j \omega L_{P}+R_{P}\right) Z_{S}+\omega^{2} k^{2}\left(L_{P} L_{S}\right)} .
$$

Therefore, the voltage gain of the proposed circuit can be expressed as Equation (9)

$$
\left|\frac{V_{O}}{V_{\text {in }}}\right|=\frac{\omega k \sqrt{L_{P} L_{S}}}{\sqrt{\left(\omega L_{P}\right)^{2}+\left(R_{P} Z_{S}+\omega^{2} k^{2} L_{P} L_{S}\right)^{2}}} \frac{R_{e q}}{(1-D) \sqrt{\left(\omega C_{S} R_{e q}\right)^{2}+1}} .
$$

Equation (9) shows that the output voltage can be controlled by duty cycle $D$, coupling coefficient $k$, switching frequency $f$ and the equivalent resistance $R_{e q}$. However, frequency $f$ and the load $R$ usually are constant in the proposed circuit, thus the output voltage can be regulated by the duty cycle $D$ of the push-pull switches $S_{1}$ and $S_{2}$.

Compared with traditional full-bridge circuit, its equivalent $\mathrm{AC}$ input $U_{A B}$ can be calculated by

$$
U_{A B}=\frac{2 \sqrt{2} V_{i n}}{\pi} .
$$

In addition, the voltage gain of the full-bridge converter will be

$$
\left|\frac{V_{O}}{V_{i n}}\right|=\frac{\omega k \sqrt{L_{P} L_{S}}}{\sqrt{\left(\omega L_{P}\right)^{2}+\left(R_{P} Z_{S}+\omega^{2} k^{2} L_{P} L_{S}\right)^{2}}} \frac{2 \sqrt{2} R_{e q}}{\pi \sqrt{\left(\omega C_{S} R_{e q}\right)^{2}+\pi}} .
$$

As can be seen from Equations (9) and (11), we can draw a conclusion that the voltage gain of proposed topology can be at least two times than traditional full-bridge topology.

Compared with a traditional push-pull circuit, its equivalent AC input $U_{A B}$ can be calculated by 


$$
U_{A B}=\frac{\pi V_{i n}}{\sqrt{2}}
$$

Furthermore, the voltage gain of the full-bridge converter will be

$$
\left|\frac{V_{O}}{V_{\text {in }}}\right|=\frac{\omega k \sqrt{L_{P} L_{S}}}{\sqrt{\left(\omega L_{P}\right)^{2}+\left(R_{P} Z_{S}+\omega^{2} k^{2} L_{P} L_{S}\right)^{2}}} \frac{\pi R_{e q}}{\sqrt{2} \sqrt{\left(\omega C_{S} R_{e q}\right)^{2}+1}}
$$

As can be seen from Equations (9) and (13), we can draw a conclusion that the voltage gain of proposed topology can achieve $\frac{\sqrt{2}}{\pi(1-D)}(0.5 \leq D<1)$ times the traditional push-pull topology.

\section{System Performance Analysis}

In order to analyze the performance of the proposed method, several performance analyses are carried out including load variation, coupling coefficient and comparison with a traditional WPT system.

\subsection{Influence of Load (R) Variation on Voltage Gain and Efficiency}

According to Equation (9), Figure 5 shows the voltage gain against switching duty cycle $D$ with different load $R$, and the efficiency against load $R$ when $k=0.2$. The analysis results show

(1) With the increase of switch duty cycle $D$, the output gain enhancement increases obviously and the increasing rate of voltage gain increases gradually.

(2) The voltage gain ratio is higher when the load $R$ becomes larger at the same switching duty cycle $D$.

(3) From Figure $5 b$, the system can keep efficiency above $85 \%$ in the whole duty cycle range.

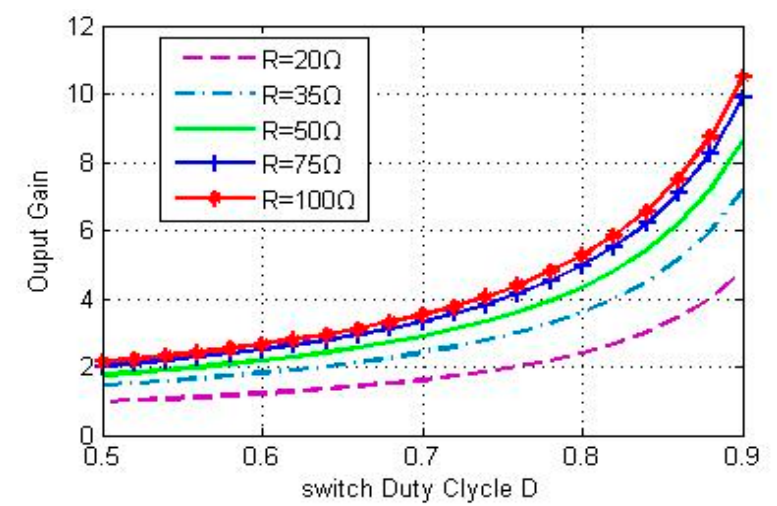

(a)

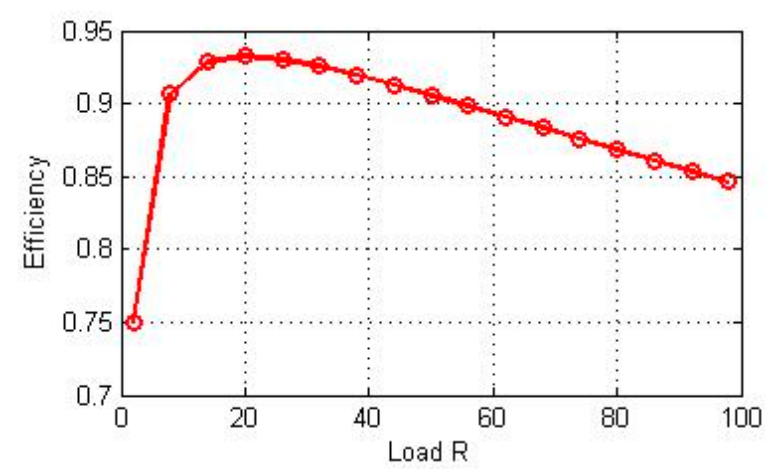

(b)

Figure 5. Influence of load $R$ : (a) Output gain with various load $R$; (b) System efficiency with load $R$.

\subsection{Influence of Coupling Coefficient ( $k$ ) Variation on the Gain Ratio and Efficiency}

Because the WPT system is a loosely coupled system, the coupling coefficient will vary dynamically. It is necessary to analyze the influence of coupling coefficient variation.

Figure 6a shows curves of voltage gain against switching duty cycle $D$ using Equation (9) at different coupling coefficients. It can be seen that the gain ratio increases as the switching duty cycle $D$ increases. The gain ratio is higher when the coupling coefficient is larger.

Figure $6 \mathrm{~b}$ shows the curves of system efficiency against different operating coupling coefficients. As the coupling coefficients $k$ increases, the efficiency decreases while load $R$ is larger. Overall, the system can keep running at efficiency above $75 \%$ on the condition of coupling coefficient and load variation. 


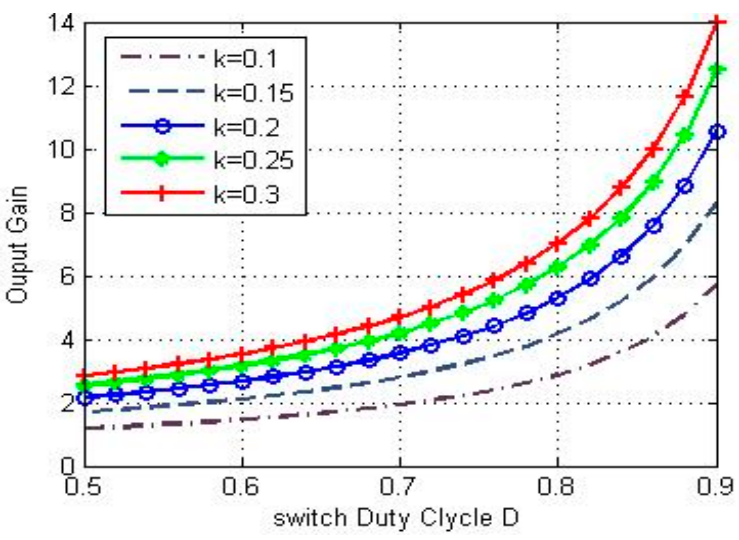

(a)

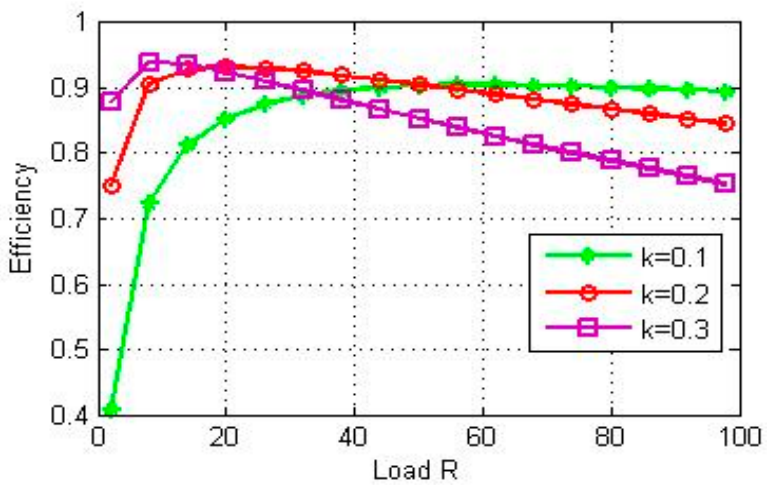

(b)

Figure 6. Influence of coupling coefficient: (a) Output gain; (b) System efficiency.

\subsection{Comparison of Traditional WPT System}

In order to compare this topology performance with traditional WPT system, this chapter presents the voltage gain of four resonant networks (PP, PS, SP and SS) with the same resonant parameters. The voltage gain and efficiency of four compensation circuits are compared against load variation range from 0 to $100 \Omega$ in Figure 7 .

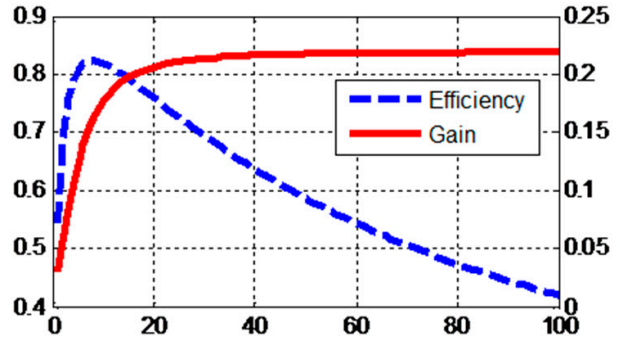

(a) PS Topology

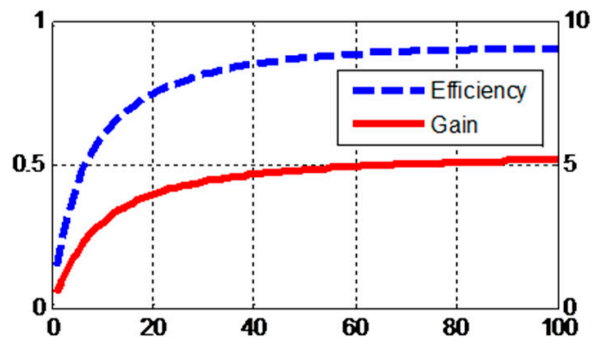

(c) SP Topology

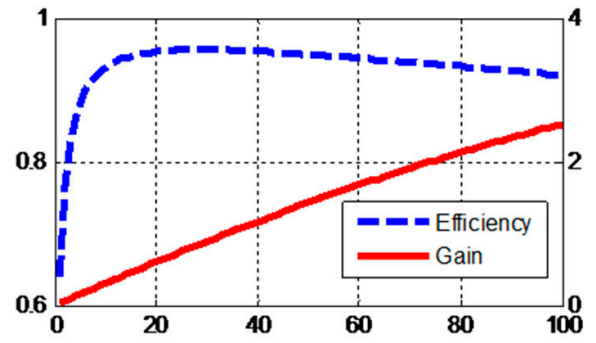

(b) PP Topology

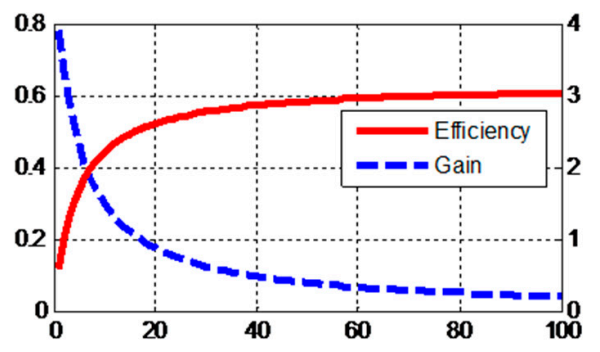

(d) SS Topology

Figure 7. Gain and efficiency of four basic compensation circuits.

In Figure 7, for secondary series topology including PS and SS, this kind of topology cannot achieve high voltage gain due to its voltage source characteristic, and its efficiency is relatively low on the light load condition. Secondary parallel topology can achieve relatively high voltage gain (maximum gain equals 5.1) due to its current source characteristic, but voltage gain varies greatly with load variation. For heavy load conditions, its voltage gain is low.

Compared with the four basic compensation circuits, the proposed push-pull circuit can operate at an adjustable gain versus load $R$ with high efficiency from the analyses $A$ and $B$. 


\section{Experimental Verification}

For the sake of verifying the performance of the proposed topology, a prototype system is built up. The system has been constructed according to the parameters provided in Table 1 and the device photo is shown in Figure 8.

Table 1. System parameters.

\begin{tabular}{cc}
\hline Parameters & Values \\
\hline Resonant frequency $f(\mathrm{KHz})$ & 31.45 \\
Primary resonant inductor $L_{P}(\mu \mathrm{H})$ & 30.38 \\
Primary inductor resistance $R_{P}(\Omega)$ & 0.025 \\
Primary capacitor $C_{P}(\mu \mathrm{F})$ & 0.66 \\
Secondary resonant inductor $L_{S}(\mu \mathrm{H})$ & 36.82 \\
Secondary inductor resistance $R_{S}(\Omega)$ & 0.029 \\
Secondary resonant capacitor $C_{S}(\mu \mathrm{F})$ & 0.57 \\
Coupling coefficient $k$ & 0.157 \\
System load $R(\Omega)$ & 50 \\
\hline
\end{tabular}

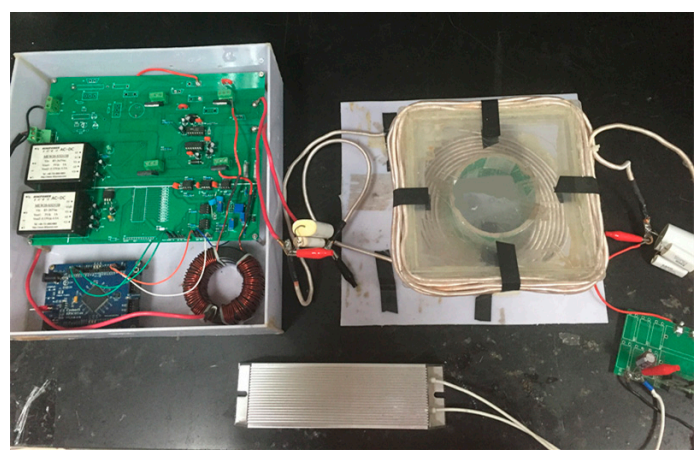

Figure 8. Experimental system photo.

Figure 9 shows the waveforms of the push-pull switches gate-driving signals and anti-series switching gate-driving signals. The resonant voltage $V_{C P}$ and resonant current $I_{L P}$ are shown in Figure 10 and the resonant voltage and current waveforms are sinusoidal waves, which indicate that the system can work under the state of resonance.

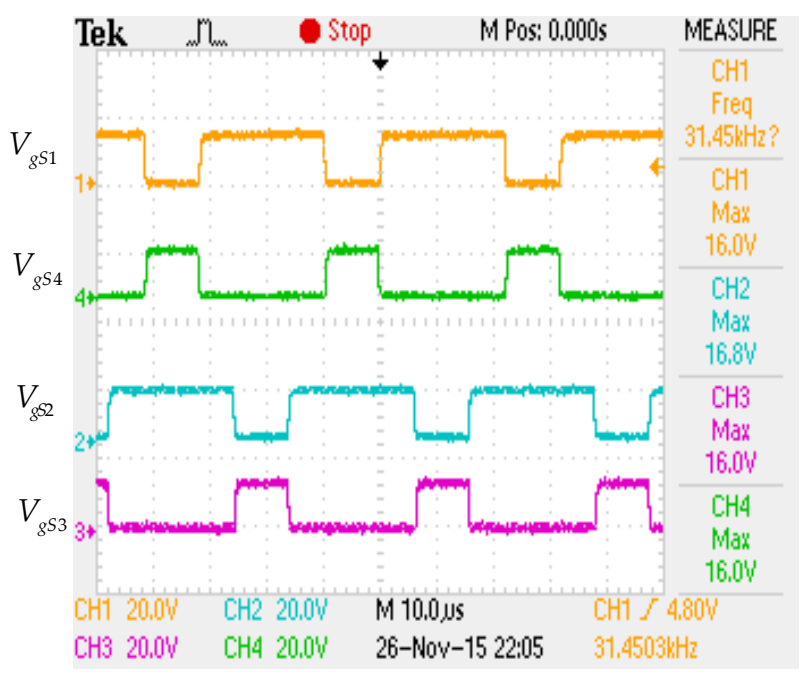

Figure 9. Gate-driving signals' waveforms. 


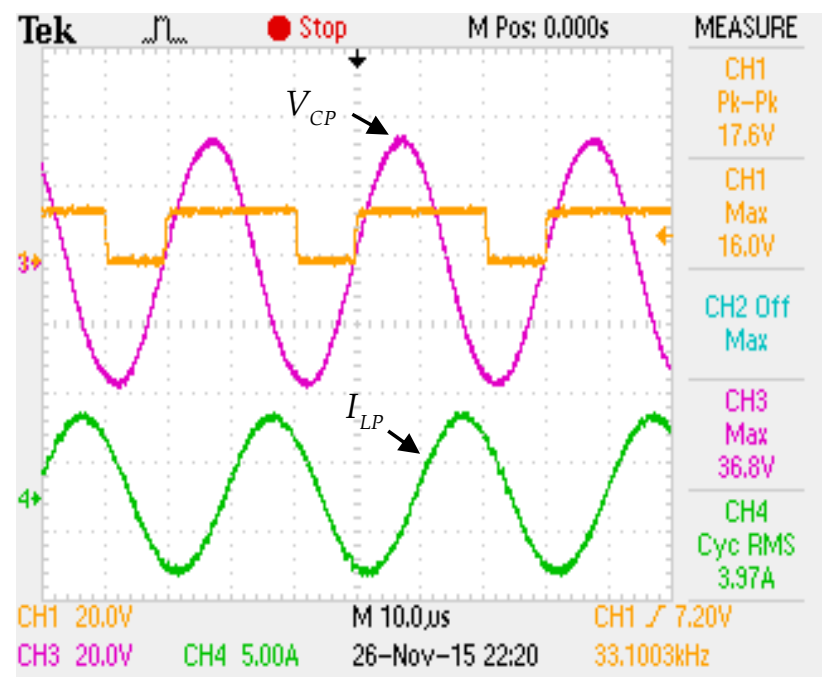

Figure 10. Resonant voltage and resonant current waveforms.

Figure 11 shows the waveforms of $V_{d S 2}, V_{d S 3}$ and $V_{C P}$ from top to bottom. It can be seen that the synthesized waves of $V_{d S 2}$ and $V_{d S 3}$ are exactly half of the resonant wave $V_{C P}$ on the condition of $D=0.6$. The same result can be detected that the synthesized waves of $V_{d S 1}$ and $V_{d S 4}$ are exactly half of the resonant wave $V_{C P}$. When the duty cycle becomes $D=0.8$, the waveforms of $V_{d S 2}, V_{d S 3}$ and $V_{C P}$ are shown in Figure 12 and $V_{d S 2}$ and $V_{d S 3}$ are changing when the duty cycle $D$ is changing. Figure 13 shows that $V_{O}$ is controlled at $43 \mathrm{~V}$ for the condition of $R=50 \Omega$ and $D=0.8$, which achieves a gain of 4.3 times compared with the input voltage $U_{i n}=10 \mathrm{~V}$. It verifies that the system can realize a higher gain by regulating the duty cycle $D$.

Table 2 presents the experimental data of the proposed topology. The controlled gain range is from 1.6 to 7.3. With higher gain, the system can get higher output power. Furthermore, system efficiency can remain above $80 \%$. Figure 14 shows that the experimental results of voltage gain match with the theoretical results well, except that there is little difference at the maximum gain point. It is because power losses at the primary side will increase at the top gain point.

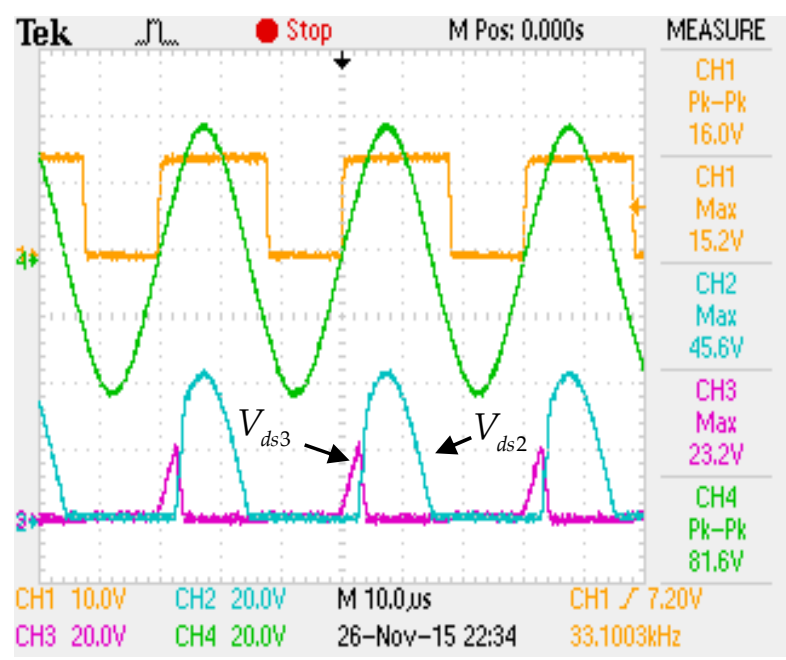

Figure 11. Waveforms of $V_{d S 2}, V_{d S 3}$ and $V_{C p}$ at $D=0.6$. 


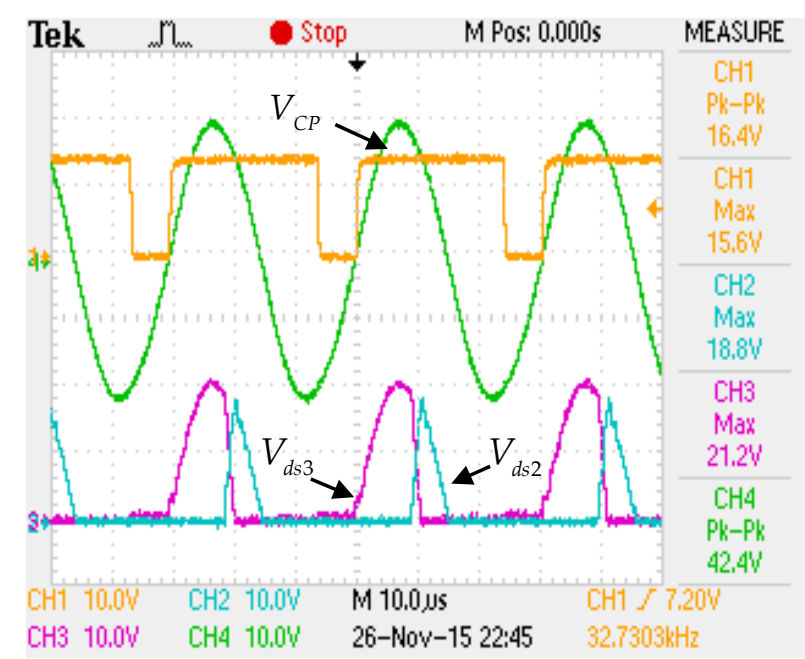

Figure 12. Waveforms of $V_{d S 2}, V_{d S 3}$ and $V_{C p}$ at $D=0.8$.

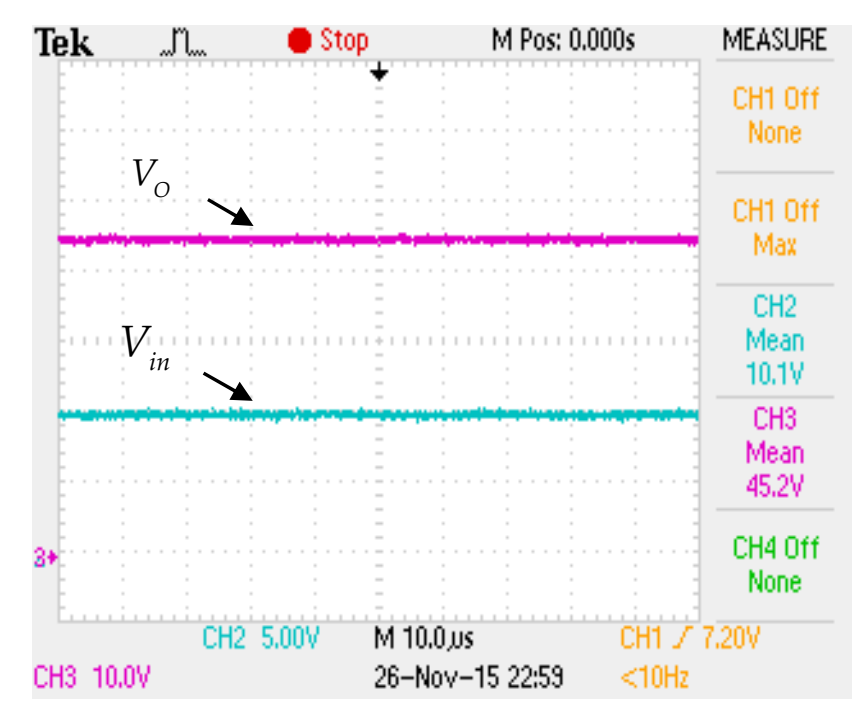

Figure 13. Waveforms of input voltage and output voltage.

Table 2. Experiment Results.

\begin{tabular}{cccccc}
\hline $\begin{array}{c}\text { Input Voltage/Current } \\
\text { (V/A) }\end{array}$ & $\begin{array}{c}\text { Duty Cycle } \\
\text { of } \boldsymbol{S}_{\mathbf{1}}(\mathbf{D})\end{array}$ & $\begin{array}{c}\text { Output } \\
\text { Voltage (V) }\end{array}$ & $\begin{array}{c}\text { Output } \\
\text { Power (W) }\end{array}$ & Gain & Efficiency \\
\hline $10 / 0.61$ & 0.5 & 16.2 & 5.4 & 1.6 & $88 \%$ \\
$10 / 1.09$ & 0.6 & 21.7 & 9.5 & 2.17 & $87.4 \%$ \\
$10 / 1.96$ & 0.7 & 28.9 & 16.9 & 2.89 & $86 \%$ \\
$10 / 2.80$ & 0.75 & 34.5 & 23.8 & 3.45 & $85 \%$ \\
$10 / 4.7$ & 0.8 & 43.1 & 39.5 & 4.31 & $84.1 \%$ \\
$10 / 8.08$ & 0.85 & 53.8 & 67.5 & 5.38 & $83.6 \%$ \\
$10 / 15.2$ & 0.9 & 72.3 & 123 & 7.3 & $80.9 \%$ \\
\hline
\end{tabular}




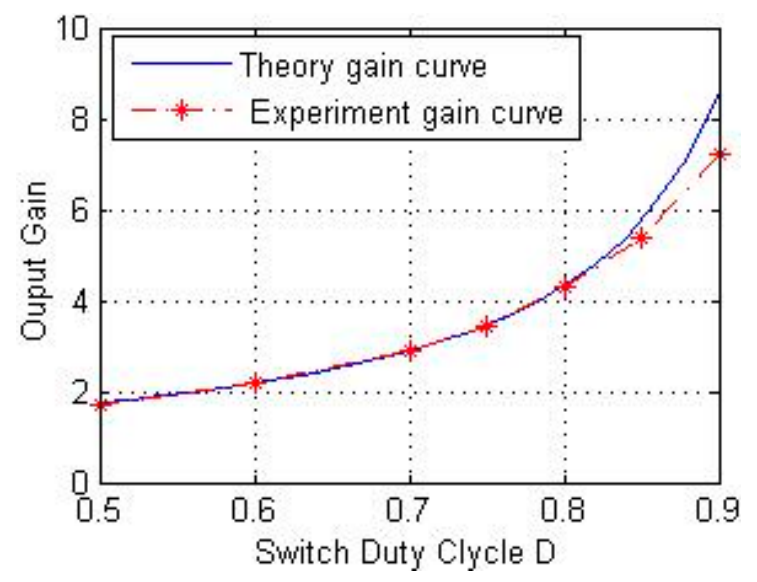

Figure 14. Comparison of the system gain curve.

\section{Discussion}

In order to present a close loop control of the voltage gain, a Proportion Integration Differentiation (PID) control is applied to regulate the duty cycle $D$ of the switches. The close loop control structure can be shown in Figure 15.

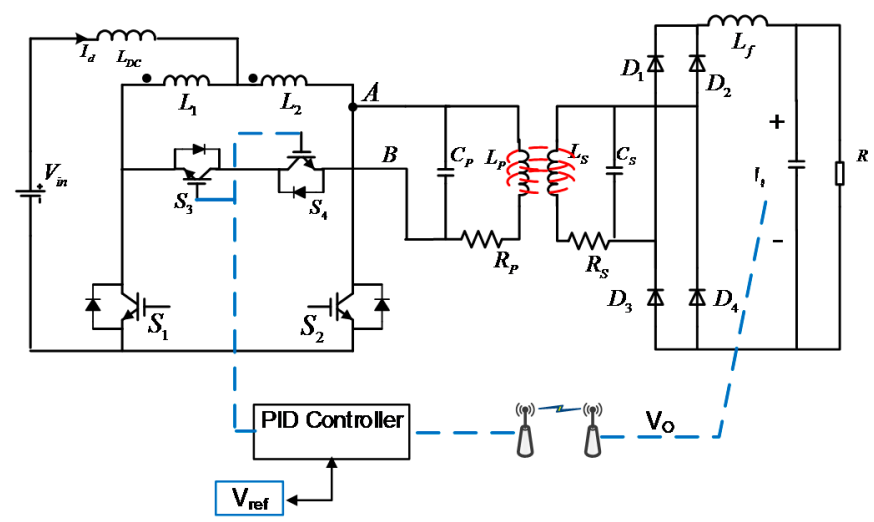

Figure 15. Close loop control.

The information of output voltage $\mathrm{V}_{\mathrm{O}}$ is measured and sent back to the primary side by an Radio Frequency (RF)-link. Furthermore, a PID controller is utilized to control the duty cycle of $S_{3}$ and $S_{4}$, according to the difference between $V_{O}$ and $V_{\text {ref }}$.

A load switching test was carried out to evaluate the controller's performance. In this test, load condition is set to switching between $10 \Omega$ and $30 \Omega$. The DC input voltage is set at $5 \mathrm{~V}$. The output reference voltage is set at $20 \mathrm{~V}$. The experimental result can be shown in Figure 16.

As can be seen in Figure 16, there are two load switching events in the control process: one is from $20 \Omega$ to $10 \Omega$ (first switching) and the other is from $10 \Omega$ to $20 \Omega$ (second switching). In the control process, the output voltage is kept stable except for some switching disturbance. The experimental results verify the close loop control performance of the PID controller. 


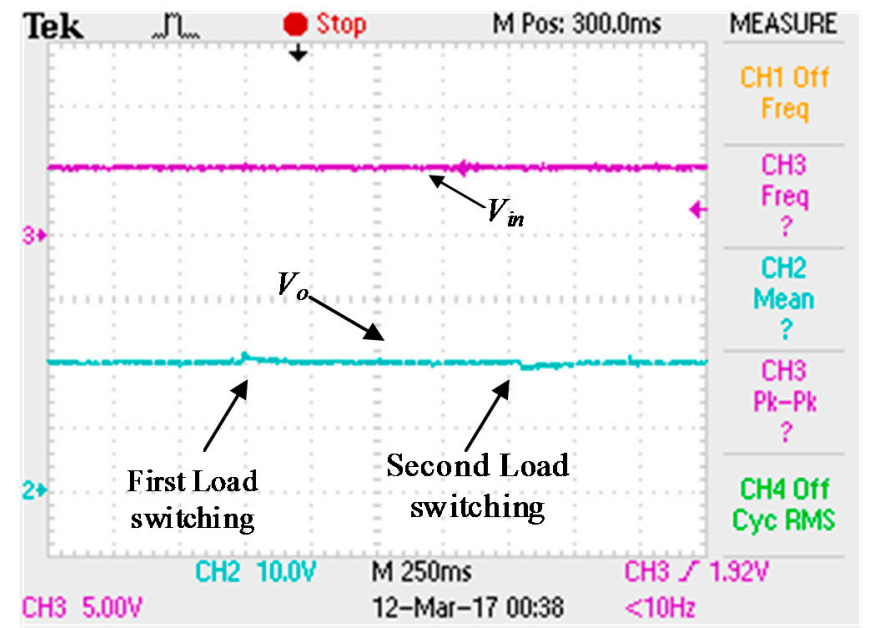

Figure 16. Experimental results of close loop control.

\section{Conclusions}

In order to achieve controllable high voltage gain output, this paper proposed a novel current-fed push-pull topology for the WPT system. This method utilizes a bi-directional switch that is added to isolate the inverter with resonant network and guide the power flow into the resonant tank. On the basis, an energy storage and injection switching mode is proposed to enhance voltage gain. A switching duty cycle is also proposed to implement gain control. This method can greatly improve the voltage gain in the WPT system and maintain a high system efficiency at the same time. This is important for low DC voltage input application including PV power supply and USB charger.

Acknowledgments: This research works is support by the National Natural Science Foundation of China (51377187, 51377183) and the Chongqing International Science and Technology Cooperation Base Project (CSTC2015GJHZ40001).

Author Contributions: The main idea of this paper is proposed by Qichang Duan and Yanling Li. Yanling Li wrote this paper. Xin Dai gave experiment design. Tao Zou performed verification experiments.

Conflicts of Interest: The authors declare no conflict of interest.

\section{References}

1. Geng, Y.; Yang, Z.; Lin, F.; Hu, S. A High Efficiency Charging Strategy for a Supercapacitor Using a Wireless Power Transfer System Based on Inductor/Capacitor/Capacitor (LCC) Compensation Topology. Energies 2017, 10, 135. [CrossRef]

2. Jinwook, K.; Hyeon-Chang, S.; Do-Hyeon, K. Optimal Design of a Wireless Power Transfer System with Multiple Self-Resonators for an LED TV. IEEE Trans. Consum. Electron. 2012, 58, 775-780.

3. RamRakhyani, A.K.; Lazzi, G. On the Design of Efficient Multi-Coil Telemetry System for Biomedical Implants. IEEE Trans. Biomed. Circuits Syst. 2013, 7, 11-23. [CrossRef] [PubMed]

4. Dai, X.; Sun, Y. An Accurate Frequency Tracking Method Based on Short Current Detection for Inductive Power Transfer System. IEEE Trans. Ind. Electron. 2014, 61, 776-783. [CrossRef]

5. Zou, Y.; Dai, X.; Li, W.; Sun, Y. Robust Design Optimization for Inductive Power Transfer Systems from Topology Collection Based on an Evolutionary Multi-Objective Algorithm. IET Power Electron. 2015, 8, 1767-1776. [CrossRef]

6. Ho, Y.L.; Budgett, D.M.; Hu, A.P. Minimizing Power Loss in Air-Cored Coils for TET Heart Pump Systems. IEEE J. Emerg. Sel. Top. Circuits Syst. 2011, 1, 412-419.

7. Kuo, N.C.; Zhao, B.; Niknejad, A.M. Bifurcation Analysis in Weakly-Coupled Inductive Power Transfer Systems. IEEE Trans. Circuits Syst. I Regul. Pap. 2016, 63, 727-738. [CrossRef]

8. Hu, A.P.; You, Y.W.; Chen, F.B. Wireless Power Supply for ICP Devices with Hybrid Supercapacitor and Battery Storage. IEEE J. Emerg. Sel. Top. Power Electron. 2016, 4, 273-279. [CrossRef] 
9. Jittakort, J.; Yachiangkam, S.; Sangswang, A. A Variable-frequency Asymmetrical Voltage-Cancellation Control of Series Resonant Inverters in Domestic Induction Cooking. In Proceedings of the 2011 IEEE 8th International Conference on Power Electronics and ECCE Asia (ICPE 2011-ECCE Asia), Jeju, Korea, 30 May-3 June 2011; pp. 2320-2327.

10. Kim, N.Y.; Kim, K.Y.; Choi, J. Adaptive Frequency with Power-Level Tracking System for Efficient Magnetic Resonance Wireless Power Transfer. Electron. Lett. 2012, 48, 452-454. [CrossRef]

11. Huanmin, W.; Hui, Z.; Yanting, L. Analysis on Wireless Charging Circuit Characteristic Under The Hybrid Compensation Topology. In Proceedings of the 2016 IEEE 8th International Power Electronics and Motion Control Conference (IPEMC 2016-ECCE Asia), Hefei, China, 22-26 May 2016; pp. 2450-2454.

12. Dai, X.; Zou, Y.; Sun, Y. Uncertainty Modeling and Robust Control for LCL Resonant Inductive Power Transfer System. J. Power Electron. 2013, 13, 814-828. [CrossRef]

13. Neath, M.J.; Swain, A.; Madawala, U. An Optimal PID Controller for a Bidirectional Inductive Power Transfer System Using Multi-objective Genetic Algorithm. IEEE Trans. Power Electron. 2013, 29, 1523-1531. [CrossRef]

14. Gao, Y.; Farley, K.B.; Tse, Z.T. A uniform voltage gain control for alignment robustness in wireless EV charging. Energies 2015, 8, 8355-8370. [CrossRef]

15. Abdolkhani, A.; Hu, A.P. A Novel Detached Magnetic Coupling Structure for Contactless Power Transfer. In Proceedings of the 37th Annual Conference of IEEE Industrial Electronics (IECON 2011), Melbourne, Australia, 7-10 November 2011; pp. 1103-1108.

16. Hou, J.; Chen, Q.; Yan, K.; Ren, X.; Wong, S.C.; Tse, C.K. Analysis and Control of S/Sp Compensation Contactless Resonant Converter with Constant Voltage Gain. In Proceedings of the 2013 IEEE Energy Conversion Congress and Exposition (ECCE), Denver, CO, USA, 15-19 September 2013; pp. 2552-2558.

(C) 2017 by the authors. Licensee MDPI, Basel, Switzerland. This article is an open access article distributed under the terms and conditions of the Creative Commons Attribution (CC BY) license (http://creativecommons.org/licenses/by/4.0/). 